\title{
Effect of periodontitis on the development of osteoporosis: results from a nationwide population-based cohort study (2003-2013) \\ (1) CrossMark
}

\author{
Jung-Kyu Choi ${ }^{1}$, Young-Taek Kim², Hye-In Kweon ${ }^{2}$, Eun-Cheol Park ${ }^{3,4}$, Seong-Ho Choi ${ }^{5^{*+}}$ and Jae-Hong Lee ${ }^{6^{*+}}$ (D)
}

\begin{abstract}
Background: The prevalence of osteoporosis associated with the aging process is anticipated to increase along with the rising aging population. Periodontitis that the most common chronic infections of humankind is considered the risk factor for osteoporosis. The aim of this study was to identify the association between osteoporosis and periodontitis using a population-based cohort.

Methods: The case group was defined as patients diagnosed with periodontitis and treated with subgingival curettage, root conditioning, periodontal flap operation, bone grafting for alveolar bone defects, and guided tissue regeneration. Case and control groups matched for gender, age, household income, type of social security, disability, and residential area were generated. A Cox proportional hazard model was constructed to examine the difference in the development of osteoporosis between the case and control groups. The final sample included 13,464 participants.

Results: The incidence of osteoporosis was $1.1 \%$ in males and $15.8 \%$ in females during a 10-year period. The risk factors for osteoporosis in males were increasing age and Charlson Comorbidity Index score. Periodontitis was not associated with the development of osteoporosis in males. The risk factors for osteoporosis in females were increasing age, body mass index, Charlson Comorbidity Index score, diabetes, and periodontitis. Women with periodontitis were more likely to also develop osteoporosis (HR: 1.22, 95\% Cl: 1.01-1.48).

Conclusions: Periodontitis has an effect on the development of osteoporosis in females. Managing good teeth is required for the prevention and delay of osteoporosis. This includes dental examinations, regular cleanings and gum treatment.
\end{abstract}

Keywords: Osteoporosis, Periodontitis, Cohort study, Female, Middle-aged

\section{Background}

Osteoporosis is a common disease related to fractures that occur at multiple skeletal sites. It causes significant morbidity and mortality [1] and is the most common reason for a broken bone among the elderly. Osteoporosis has no symptoms; it is defined as a deterioration of bone tissues and is a skeletal disorder characterized by

\footnotetext{
*Correspondence: shchoi726@yuhs.ac; ljaehong@gmail.com

${ }^{\dagger}$ Equal contributors

${ }^{5}$ Department of Periodontology, Yonsei University College of Dentistry, 50 Yonsei-ro, Seodaemun-gu, Seoul 03722, Korea

${ }^{6}$ Department of Periodontology, Wonkwang University Daejeon Dental Hospital, Wonkwang University College of Dentistry, 77, Dunsan-ro, Seo-gu, Daejeon 35233, Korea

Full list of author information is available at the end of the article
}

low bone mass, which is a risk factor for an increased incidence of fracture $[2,3]$. In females, bone loss increases after menopause due to lower levels of estrogen. The most common locations for osteoporotic fractures are the hip, wrist and spine.

The prevalence of osteoporosis associated with the aging process is anticipated to increase along with the increasing age of the general population. The crude prevalence rates of osteoporosis in both males and females aged $40-79$ were $13.1 \%$ and $24.3 \%$, respectively, in Korea [4]. In addition, osteoporosis is associated with a reduced health-related quality of life [5].

Periodontal diseases are closely associated with other non-communicable diseases and are the most 
common diseases across the globe [6]. Periodontal disease itself is caused by infection and inflammation inside the mouth after plaque has been left on the teeth for far too long. The condition occurs in 5-20\% of the adult population in both developed and developing countries [7-11]. In Korea, the overall prevalence rate of periodontitis was $31.3 \%$ [12, 13]. In 2014, $24.9 \%$ of the Korean population received treatment for periodontitis, the second highest frequency of disease, and US $\$ 880$ million were spent on these treatments. The annual direct per-capita medical costs of periodontitis were US $\$ 68$ [14].

Risk factors of osteoporosis include female gender, increasing age, low body mass index (BMI), lifestyle factors (smoking, alcohol intake), menopause, and the use of medications including glucocorticoids, anticonvulsants and anticoagulants [15-19]. Osteoporosis and periodontitis share a common mechanism of action due to prostaglandins and proinflammatory cytokines $[20,21]$. Periodontitis is regarded as a risk factor for comorbid diseases, such as cardiovascular and chronic inflammatory disease [22-24]. A recent large-scale cohort study identified a significant association between periodontitis and osteoporosis [12, 25]. Therefore, we hypothesized that periodontitis would be associated with the development of osteoporosis. The aim of this study was to investigate an association between osteoporosis and periodontitis using a representative population-based cohort. Gender-specific analyses were conducted, and a number of potential confounding variables were examined.

\section{Methods}

\section{Participants}

This study used National Health Insurance Service (NHIS) cohort data released in Korea. The dataset was comprised of 1,025,340 nationally representative participants and employed stratified sampling by gender, age and income level. The participants accounted for approximately $2.2 \%$ of the Korean population in 2002. The dataset also includes information on all medical claims filed and checkups attended by participants from 2002 to 2013.

Participants who were under 30 years of age, had been diagnosed with both osteoporosis in $2002 \sim 2004$ and periodontitis in $2002 \sim 2003$, and had no data related to a checkup in $2002 \sim 2003$ were excluded from our analyses. Case and control groups were matched for gender, age, household income, type of Social Security, disability, and residential area using propensity score matching (PSM). The final sample included 13,464 participants: 8884 males and 4580 females. The case group included patients who were diagnosed with periodontitis. A statistical matching technique named PSM was conducted to reduce the bias due to confounding variables between the case and control group.

\section{Definition of periodontitis}

Patients were defined as having periodontitis as per the 2004 International Classification of Disease 10th (ICD10), code K05.3-K05.6 and been treated with subgingival curettage, root conditioning, periodontal flap operation, bone graft for alveolar bone defects, and guided tissue regeneration (Prescription code of NHIS: U1051-1052 Periodontal flap operation [Simple/complicated], U1071-1072 bone graft for alveolar bone defects [allogenic, xenogenous or substitute bone graft/autogenous bone graft], U10811083 guided tissue regeneration [without bone graft/allogenic, xenogenous or substitute bone graft/autogenous bone graft]).

\section{Definition of osteoporosis}

The diagnosis of osteoporosis was the dependent variable. According to the ICD-10, osteoporosis was designated with main codes M80-M82. The different types of osteoporosis include osteoporosis with pathological fracture (M80), osteoporosis without pathological fracture (M81) and osteoporosis in diseases classified elsewhere (M82). Patients with osteoporosis were defined as those who visited clinics or hospitals at least two times per year for the condition and underwent bone densitometry.

\section{Confounding variables}

Confounding variables included gender, baseline age, type of Social Security, income level, disability, residential area, Charlson Comorbidity Index (CCI), hypertension and diabetes mellitus, BMI, smoking, alcohol, and physical activity. Age was divided into four groups by 10 -year periods $(30-39,40-49,50-59$, and $60+$ years). The type of Social Security consisted of medical aid and health insurance in Korea. Health insurance was divided into industrial worker (IW) and self-employer (SE). The participants' income level was recoded into five categories, from quintile 1 (low) to quintile 5 (high), according to the insurance premiums of all people in the household. The disability category was divided into normal and handicapped groups. The residential area was divided into either urban or rural. The CCI was calculated as the sum of the score of comorbid conditions (out of 22 total conditions). Each condition was assigned a score of 1 , 2,3 , or 6 . The CCI was coded again into three categories $(0,1, \geq 2)[26,27]$. The hypertension and diabetes mellitus patients were participants who had been diagnosed with I10-I15 and E10-E14 in 2003. BMI was calculated as the patient's weight in kilograms divided by the square of their height in meters. BMI was categorized as underweight (under $18.5 \mathrm{~kg}$ / $\mathrm{m}^{2}$ ), normal weight $\left(18.5-23 \mathrm{~kg} / \mathrm{m}^{2}\right)$, overweight $(23-$ $27.5 \mathrm{~kg} / \mathrm{m}^{2}$ ), and obese (over $27.5 \mathrm{~kg} / \mathrm{m}^{2}$ ) [28]. Participants were classified into non-smoker, ex-smoker and 
smoker groups. The alcohol frequency was divided into none, $2-3 /$ month, $1-2 /$ week, $3-4 /$ week, and $\geq 5$ / week. Physical activity was divided into none, 1-2/ week, 3-4/week, 5-6/week, and 7/week according to the participants' weekly frequency.

\section{Statistical analysis}

All statistical analyses were conducted separately for each gender. We compared independent variables using $\mathrm{x}^{2}$-test according to the presence of periodontitis. The results were expressed as frequency (\%). A Cox proportional hazard model was created to examine the differences in the development of osteoporosis between the study and the control group. Covariates included baseline age (ref: 30-39 years old), income level (ref: 1 quintile), type of Social Security (ref: Health insurance (IW)), disability (ref: normal), residential area (ref: urban), smoking (ref: non-smoker), alcohol (ref: none), physical activity (ref: none), BMI (ref: $18.5-23 \mathrm{~kg} / \mathrm{m}^{2}$ ), CCI (ref: 0), hypertension (ref: non-diagnosed), and diabetes mellitus (ref: non-diagnosed). The overall incidence rate by age group $(30-49,50+)$ was calculated using a Kaplan-Meier curve for the 11-year follow-up period. The survival time was the number of months between the baseline and when osteoporosis was identified. The SAS statistical package version 9.2 was used to perform the analyses in this study. A $p$-value $<0.05$ was considered to be significant.

Table 1 Characteristics of the subjects according to diagnosis of periodontitis (male)

\begin{tabular}{|c|c|c|c|c|c|c|c|c|}
\hline & & \multicolumn{2}{|l|}{ Total } & \multicolumn{2}{|c|}{ Non-Diagnosed } & \multicolumn{2}{|c|}{ Diagnosed } & \multirow[b]{2}{*}{$P$-value } \\
\hline & & $\bar{N}$ & $\%$ & $N$ & $\%$ & $N$ & $\%$ & \\
\hline Total & & 8884 & 100 & 7403 & 83.3 & 1481 & 16.7 & \\
\hline \multirow[t]{4}{*}{ Age } & $30 \sim 39$ & 2592 & 29.2 & 2160 & 83.3 & 432 & 16.7 & 1.0000 \\
\hline & $40 \sim 49$ & 3412 & 38.4 & 2843 & 83.3 & 569 & 16.7 & \\
\hline & $50 \sim 59$ & 1860 & 20.9 & 1550 & 83.3 & 310 & 16.7 & \\
\hline & $\geq 60$ & 1020 & 11.5 & 850 & 83.3 & 170 & 16.7 & \\
\hline \multirow[t]{3}{*}{ Smoking } & Non-smoker & 3560 & 40.1 & 2992 & 84.0 & 568 & 16.0 & 0.2452 \\
\hline & Ex-smoker & 773 & 8.7 & 648 & 83.8 & 125 & 16.2 & \\
\hline & Smoker & 4551 & 51.2 & 3763 & 82.7 & 788 & 17.3 & \\
\hline \multirow[t]{5}{*}{ Alcohol } & None & 2757 & 31.0 & 2286 & 82.9 & 471 & 17.1 & 0.8023 \\
\hline & $2 \sim 3 /$ month & 2049 & 23.1 & 1716 & 83.7 & 333 & 16.3 & \\
\hline & $1 \sim 2 /$ week & 2612 & 29.4 & 2183 & 83.6 & 429 & 16.4 & \\
\hline & $3 \sim 4 /$ week & 998 & 11.2 & 823 & 82.5 & 175 & 17.5 & \\
\hline & $\geq 5 /$ week & 468 & 5.3 & 395 & 84.4 & 73 & 15.6 & \\
\hline \multirow[t]{4}{*}{ Physical activity } & None & 4253 & 47.9 & 3563 & 83.8 & 690 & 16.2 & 0.4111 \\
\hline & $1 \sim 2 /$ week & 2920 & 32.9 & 2434 & 83.4 & 486 & 16.6 & \\
\hline & $3 \sim 4 /$ week & 993 & 11.2 & 810 & 81.6 & 183 & 18.4 & \\
\hline & $5 \sim 7 /$ week & 718 & 8.1 & 596 & 83.0 & 122 & 17.0 & \\
\hline \multirow[t]{4}{*}{$\mathrm{BMI}\left(\mathrm{kg} / \mathrm{m}^{2}\right)$} & $<18.5$ & 180 & 2.0 & 160 & 88.9 & 20 & 11.1 & 0.0001 \\
\hline & $18.5 \sim 23$ & 2990 & 33.7 & 2545 & 85.1 & 445 & 14.9 & \\
\hline & $23 \sim 27.5$ & 4763 & 53.6 & 3938 & 82.7 & 825 & 17.3 & \\
\hline & $>27.5$ & 951 & 10.7 & 760 & 79.9 & 191 & 20.1 & \\
\hline \multirow[t]{3}{*}{$\mathrm{CCl}$} & 0 & 6310 & 71.0 & 5262 & 83.4 & 1048 & 16.6 & 0.9692 \\
\hline & 1 & 1691 & 19.0 & 1407 & 83.2 & 284 & 16.8 & \\
\hline & $\geq 2$ & 883 & 9.9 & 734 & 83.1 & 149 & 16.9 & \\
\hline \multirow[t]{2}{*}{ Hypertension } & NO & 8277 & 93.2 & 6897 & 83.3 & 1380 & 16.7 & 0.9829 \\
\hline & YES & 607 & 6.8 & 506 & 83.4 & 101 & 16.6 & \\
\hline \multirow[t]{2}{*}{ Diabetes } & NO & 8568 & 96.4 & 7141 & 83.3 & 1427 & 16.7 & 0.8391 \\
\hline & YES & 316 & 3.6 & 262 & 82.9 & 54 & 17.1 & \\
\hline \multirow[t]{2}{*}{ Osteoporosis } & NO & 8787 & 98.9 & 7326 & 83.4 & 1461 & 16.6 & 0.2942 \\
\hline & YES & 97 & 1.1 & 77 & 79.4 & 20 & 20.6 & \\
\hline
\end{tabular}

IW industrial worker, SE self-employer, BMI body mass index, CCI Charlson comorbidity index 


\section{Results}

Table 1 shows the characteristics of the case and control group in males. No significant difference in gender, age, household income, type of Social Security, disability, or residential area between the case and control groups were identified because these variables were used for matching. The rates of overweight (BMI: $23-27.5 \mathrm{~kg} / \mathrm{m}^{2}$ ) and obesity (BMI: $>27.5 \mathrm{~kg} / \mathrm{m}^{2}$ ) in the case group were significantly higher than in the control group. Osteoporosis in males developed at a rate of $1.1 \%$ over 11 years. The average duration of osteoporosis at diagnosis was 10.79 years in patients with periodontitis which was lower than the duration in participants without periodontitis (10.83 years) (data not shown). Table 2 shows the characteristics of the case and control groups in females. The case group was more likely to experience diabetes than the control group. Osteoporosis in females developed at a rate of $15.8 \%$ over 11 years. The average duration of osteoporosis at diagnosis was 9.37 years in patients with periodontitis which was significantly lower than in participants without periodontitis (9.67 years, data not shown).

Table 3 contains the HRs for osteoporosis during an 11-year follow-up period using multivariate Cox proportional regression between males and females. In males, periodontitis was not associated with the development of osteoporosis. The risk factors for osteoporosis were increasing age and CCI score. In females, the risk factors

Table 2 Characteristics of the subjects according to diagnosis of periodontitis (female)

\begin{tabular}{|c|c|c|c|c|c|c|c|c|}
\hline & & \multicolumn{2}{|l|}{ Total } & \multicolumn{2}{|c|}{ Non-Diagnosed } & \multicolumn{2}{|c|}{ Diagnosed } & \multirow[b]{2}{*}{$P$-value } \\
\hline & & $\bar{N}$ & $\%$ & $\bar{N}$ & $\%$ & $\bar{N}$ & $\%$ & \\
\hline Total & & 4580 & 100 & 3817 & 83.3 & 763 & 16.7 & \\
\hline \multirow[t]{4}{*}{ Age } & $30 \sim 39$ & 672 & 14.7 & 560 & 83.3 & 112 & 16.7 & 1.0000 \\
\hline & $40 \sim 49$ & 1926 & 42.1 & 1605 & 83.3 & 321 & 16.7 & \\
\hline & $50 \sim 59$ & 1218 & 26.6 & 1015 & 83.3 & 203 & 16.7 & \\
\hline & $\geq 60$ & 764 & 16.7 & 637 & 83.4 & 127 & 16.6 & \\
\hline \multirow[t]{3}{*}{ Smoking } & Non-smoker & 4442 & 97.0 & 3705 & 83.4 & 737 & 16.6 & 0.6548 \\
\hline & Ex-smoker & 12 & 0.3 & 9 & 75.0 & 3 & 25.0 & \\
\hline & Smoker & 126 & 2.8 & 103 & 81.7 & 23 & 18.3 & \\
\hline \multirow[t]{5}{*}{ Alcohol } & None & 3671 & 80.2 & 3025 & 82.4 & 646 & 17.6 & 0.0174 \\
\hline & $2 \sim 3 /$ month & 568 & 12.4 & 497 & 87.5 & 71 & 12.5 & \\
\hline & $1 \sim 2 /$ week & 251 & 5.5 & 218 & 86.9 & 33 & 13.1 & \\
\hline & $3 \sim 4 /$ week & 60 & 1.3 & 51 & 85.0 & 9 & 15.0 & \\
\hline & $\geq 5 /$ week & 30 & 0.7 & 26 & 86.7 & 4 & 13.3 & \\
\hline \multirow[t]{4}{*}{ Physical activity } & None & 2992 & 65.3 & 2526 & 84.4 & 466 & 15.6 & 0.0446 \\
\hline & $1 \sim 2 /$ week & 831 & 18.1 & 678 & 81.6 & 153 & 18.4 & \\
\hline & $3 \sim 4 /$ week & 374 & 8.2 & 307 & 82.1 & 67 & 17.9 & \\
\hline & $5 \sim 7 /$ week & 383 & 8.4 & 306 & 79.9 & 77 & 20.1 & \\
\hline \multirow[t]{4}{*}{$\mathrm{BMI}\left(\mathrm{kg} / \mathrm{m}^{2}\right)$} & $<18.5$ & 142 & 3.1 & 120 & 84.5 & 22 & 15.5 & 0.8475 \\
\hline & $18.5 \sim 23$ & 1922 & 42.0 & 1602 & 83.4 & 320 & 16.6 & \\
\hline & $23 \sim 27.5$ & 2026 & 44.2 & 1693 & 83.6 & 333 & 16.4 & \\
\hline & $>27.5$ & 490 & 10.7 & 402 & 82.0 & 88 & 18.0 & \\
\hline \multirow[t]{3}{*}{$\mathrm{CCl}$} & 0 & 2818 & 61.5 & 2370 & 84.1 & 448 & 15.9 & 0.074 \\
\hline & 1 & 1090 & 23.8 & 884 & 81.1 & 206 & 18.9 & \\
\hline & $\geq 2$ & 672 & 14.7 & 563 & 83.8 & 109 & 16.2 & \\
\hline \multirow[t]{2}{*}{ Hypertension } & NO & 4099 & 89.5 & 3420 & 83.4 & 679 & 16.6 & 0.6168 \\
\hline & YES & 481 & 10.5 & 397 & 82.5 & 84 & 17.5 & \\
\hline \multirow[t]{2}{*}{ Diabetes } & NO & 4407 & 96.2 & 3683 & 83.6 & 724 & 16.4 & 0.0342 \\
\hline & YES & 173 & 3.8 & 134 & 77.5 & 39 & 22.5 & \\
\hline \multirow[t]{2}{*}{ Osteoporosis } & NO & 3858 & 84.2 & 3233 & 83.8 & 625 & 16.2 & 0.0538 \\
\hline & YES & 722 & 15.8 & 584 & 80.9 & 138 & 19.1 & \\
\hline
\end{tabular}

IW industrial worker, SE self-employer, $B M I$ body mass index, CCI Charlson comorbidity index 
Table 3 Multivariate Cox proportional regression of risk factor of osteoporosis between male and female

\begin{tabular}{|c|c|c|c|c|c|c|c|}
\hline & & \multicolumn{3}{|l|}{ Male } & \multicolumn{3}{|c|}{ Female } \\
\hline & & $\mathrm{HR}$ & $95 \% \mathrm{Cl}$ & $P$-value & $\mathrm{HR}$ & $95 \% \mathrm{Cl}$ & $P$-value \\
\hline \multirow[t]{4}{*}{ Age } & $30 \sim 39$ (ref) & 1 & & & 1 & & \\
\hline & $40 \sim 49$ & 4.32 & $0.96-19.43$ & 0.057 & 8.49 & $4.34-16.60$ & $<.0001$ \\
\hline & $50 \sim 59$ & 22.99 & $5.44-97.26$ & $<.0001$ & 22.62 & $11.57-44.20$ & $<.0001$ \\
\hline & $\geq 60$ & 45.14 & 10.60-192.32 & $<.0001$ & 29.47 & $15.0-57.90$ & $<.0001$ \\
\hline \multirow[t]{3}{*}{ Smoking } & non-smoker (ref) & 1 & & & 1 & & \\
\hline & ex-smoker & 0.58 & $0.21-1.63$ & 0.301 & 1.59 & $0.22-11.45$ & 0.646 \\
\hline & smoker & 1.28 & $0.82-1.98$ & 0.273 & 0.71 & $0.43-1.18$ & 0.189 \\
\hline \multirow[t]{5}{*}{ Alcohol } & None (ref) & 1 & & & 1 & & \\
\hline & $2 \sim 3 /$ month & 0.77 & $0.40-1.46$ & 0.418 & 0.78 & $0.59-1.03$ & 0.079 \\
\hline & $1 \sim 2 /$ week & 0.95 & $0.54-1.67$ & 0.849 & 0.75 & $0.49-1.15$ & 0.188 \\
\hline & $3 \sim 4 /$ week & 0.93 & $0.46-1.89$ & 0.838 & 0.50 & $0.19-1.33$ & 0.164 \\
\hline & $\geq 5 /$ week & 1.38 & $0.72-2.65$ & 0.329 & 0.51 & $0.16-1.59$ & 0.246 \\
\hline \multirow[t]{4}{*}{ Physical activity } & None (ref) & 1 & & & 1 & & \\
\hline & $1 \sim 2 /$ week & 0.63 & $0.37-1.08$ & 0.092 & 0.83 & $0.67-1.03$ & 0.082 \\
\hline & $3 \sim 4 /$ week & 0.49 & $0.20-1.25$ & 0.135 & 0.82 & $0.61-1.11$ & 0.207 \\
\hline & $5 \sim 7 /$ week & 0.75 & $0.40-1.43$ & 0.380 & 1.02 & $0.79-1.31$ & 0.894 \\
\hline \multirow[t]{4}{*}{$\mathrm{BMI}\left(\mathrm{kg} / \mathrm{m}^{2}\right)$} & $<18.5$ & 1.31 & $0.51-3.37$ & 0.578 & 0.89 & $0.55-1.43$ & 0.632 \\
\hline & $18.5 \sim 23$ (ref) & 1 & & & 1 & & \\
\hline & $23 \sim 27.5$ & 0.92 & $0.60-1.42$ & 0.720 & 0.74 & $0.63-0.87$ & 0.000 \\
\hline & $>27.5$ & 0.33 & $0.10-1.08$ & 0.066 & 0.59 & $0.45-0.77$ & $<.0001$ \\
\hline \multirow[t]{3}{*}{$\mathrm{CCl}$} & 0 (ref) & 1 & & & 1 & & \\
\hline & 1 & 1.89 & $1.17-3.05$ & 0.010 & 1.20 & $1.00-1.43$ & 0.046 \\
\hline & $\geq 2$ & 2.25 & $1.34-3.78$ & 0.002 & 1.36 & $1.11-1.66$ & 0.003 \\
\hline \multirow[t]{2}{*}{ Hypertension } & NO (ref) & 1 & & & 1 & & \\
\hline & YES & 1.21 & $0.63-2.31$ & 0.569 & 1.03 & $0.83-1.28$ & 0.807 \\
\hline \multirow[t]{2}{*}{ Diabetes } & NO (ref) & 1 & & & 1 & & \\
\hline & YES & 1.65 & $0.65-4.15$ & 0.290 & 1.46 & $1.02-2.10$ & 0.041 \\
\hline \multirow[t]{2}{*}{ Periodontitis } & $\mathrm{NO}$ (ref) & 1 & & & 1 & & \\
\hline & YES & 1.39 & $0.85-2.29$ & 0.190 & 1.22 & $1.01-1.48$ & 0.038 \\
\hline
\end{tabular}

IW industrial worker, SE self-employer, BMI body mass index, CCI Charlson comorbidity index

of osteoporosis were increasing age, BMI, CCI score, diabetes, and periodontitis. Females with periodontitis were more likely to experience osteoporosis (HR: 1.22, 95\% CI: 1.01-1.48). Women classified as overweight (BMI: $23-27.5 \mathrm{~kg} / \mathrm{m}^{2}$ ) and obese (BMI: > $27.5 \mathrm{~kg} / \mathrm{m}^{2}$ ) were also more likely to develop osteoporosis than their normal counterparts, as were those who had been diagnosed with diabetes (HR: 1.46, 95\% CI: 1.01-1.48).

Figure 1 shows the curves that illustrate the incidence probability over an 11-year follow-up period. A subgroup analysis where gender and age $(30-49, \geq 50)$ were stratified into four groups using a Kaplan-Meier curve was conducted. The females experienced osteoporosis more frequently than males. In particular, females over the age of 50 were diagnosed with osteoporosis more frequently than females aged 30-49 years (Fig. 1c, d). The incidence of osteoporosis in participants with periodontitis was higher in this group than in any other.

\section{Discussion}

Studies on the incidence and prevalence of osteoporosis have revealed various details depending on the gender and age of the participants. In 2012, there were 4120 and 1165 patients per 100,000 in the entire Korean population who were newly diagnosed with and treated for osteoporosis [29]. In a previous Korean-oriented study, the prevalence of osteoporosis in participants over 40 and under 79 was $13.1 \%$ in males and $24.3 \%$ in females according to the World Health Organization (WHO) criteria [4]. In a different study, the prevalence 


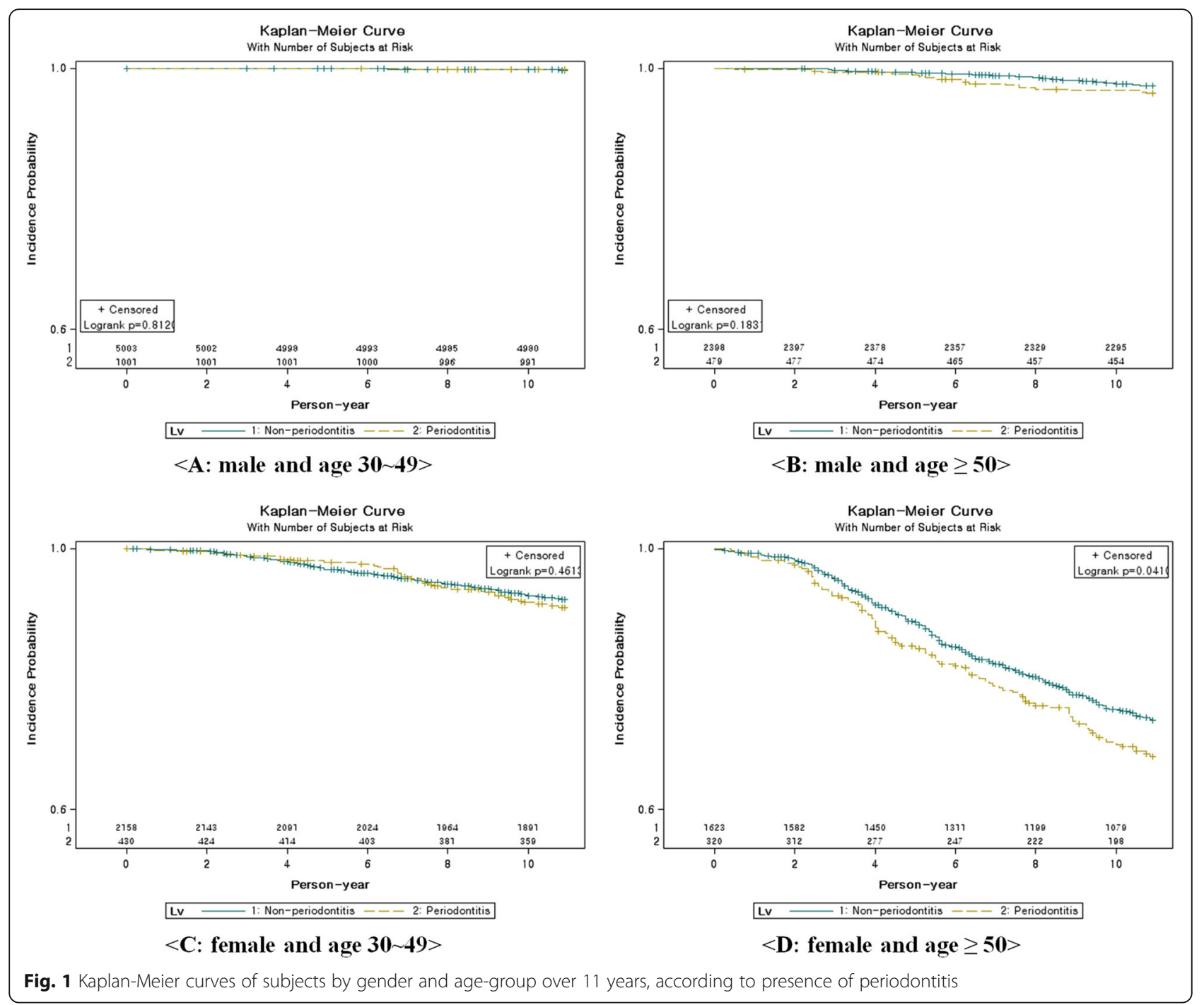

of osteoporosis in participants aged over 50 years was $35.5 \%$ in women and $7.5 \%$ in men [30]. Our study also showed a female gender tendency and dependency on age. According to these results, the crude incidence of osteoporosis was $1.1 \%$ in males and $15.8 \%$ in females over an 11-year period. In females, the average duration of osteoporosis at diagnosis for patients with periodontitis was significantly lower than the duration in patients without periodontitis.

The risk factors for osteoporosis are increasing age, BMI, $\mathrm{CCI}$ score, and periodontitis. Our findings have revealed that there is a higher risk of osteoporosis in females than in males. The gap between males and females widens after participants reach their 40 s because females experience estrogen deficiency during post-menopause [31]. An increasing age is also associated with a higher risk of osteoporosis. Estrogen and serum total testosterone levels decrease with age [32-34]. Females with a normal BMI have a significantly higher risk of osteoporosis compared with females who are overweight and obese. Participants with a higher BMI also tend to reach a higher peak bone mineral density than those with a lower BMI [35]. Comorbidities as measured by the CCI score have been associated with an increase in disease incidence. Both osteoporosis and the CCI score had a strong positive relationship [36]. The HR for the osteoporosis of subjects with CCI 1 or $\geq 2$ was also higher than for participants with a CCI of 0 . CCI score therefore has a strong influence on the development of osteoporosis in males. Lifestyle factors, such as smoking, drinking alcohol and level of physical activity, were not associated with the development of osteoporosis. However, diabetes was related with the development of osteoporosis in females. Patients with diabetes may have an increased risk for osteoporosis. Bone and mineral abnormalities in patients with diabetes might be caused by the effects of insulin deficiency or resistance and hyperglycemia on the bone and bone marrow microenvironments [37]. Males with periodontitis were not significantly associated with the 
development of osteoporosis. In contrast, females who had been diagnosed with periodontitis were significantly likely to go on to develop osteoporosis. In particular, females aged $\geq 50$ with periodontitis experienced a higher rate of osteoporosis than others.

Studies to assess the extent of the relationship between periodontitis and osteoporosis are ongoing. The findings of most studies have revealed that the reasons for the connection between the two disorders are estrogen deficiency and low bone mineral density. According to a systematic review on the relationship between periodontitis and osteoporosis, the diagnostic criteria for periodontitis serve an important function. In studies that used radiological criteria to define periodontitis, the relationship between periodontitis and osteoporosis is usually positive. However, in those investigations that used clinical criteria to define periodontitis, the results are controversial [38].

The severity of periodontitis is quickly becoming an indicator for the presence of osteoporosis elsewhere in the body, since osteoporosis associated with periodontitis is known to worsen the severity of bone degradation in the mouth. Early detection of this condition allows for more adequate treatment of osteoporosis before it has the chance to cause debilitating fractures.

The possibility of bias may arise because the obvious differences in outcome between two groups might depend on intrinsic characteristics. In randomized experimental studies, the randomization enables unbiased estimation; for each covariate, randomization implies that the case groups will be balanced on average, according to the law of large numbers [39]. However, in observational studies, the assignment of research participants is typically not randomized. Instead, PSM attempts to mimic randomization by creating a case group that is comparable on all observed covariates to a control group.

This study had the following limitations. First, the data used in our analysis were claim data and therefore only included information on each episode of health care utilization. These claim data do not contain any clinical findings or information about the disease's severity. Patients with osteoporosis were defined by examining the results of bone densitometry regardless of any other clinical findings. Second, important confounding variables, including menopause, medications, dietary factors, and metabolic syndrome, associated with osteoporosis were not available for the cohort and therefore limit the value of these findings. Previous studies have revealed the effect of menopause, medication, dietary habits, and metabolic syndrome on osteoporosis [15-17, 40, 41]. Despite these limitations, a key advantage of this study was its demonstration of an association between periodontitis and osteoporosis using 11 years of representative, population-based follow-up data. Third, claim- based diagnoses might underestimate the real prevalence or incidence of periodontitis and osteoporosis.

\section{Conclusion}

The evidence for a link between periodontitis and osteoporosis remains conflicted, so this study was conducted to further investigate this association. We found that periodontitis seems to be associated with the development of osteoporosis after matching participants for gender, age, household income, type of Social Security, disability, and residential area. In particular, females aged $\geq 50$ with periodontitis experience a higher rate of osteoporosis. To both delay and prevent osteoporosis, it is necessary for the good management of teeth. This includes dental examinations, regular cleanings and gum treatment.

\section{Abbreviations}

BMI: Body mass index; CCl: Charlson comorbidity Index; ICD: International classification of disease; IW: Industrial worker; KCD: Korean classification of diseases; NHIS: National Health Insurance Service; PSM: Propensity score matching; SE: Self-employer; WHO: World Health Organization

\section{Acknowledgements \\ Not applicable.}

\section{Funding}

This research was supported by Basic Science Research Program through the National Research Foundation of Korea (NRF) funded by the Ministry of Science \& ICT (NRF-2017R1C1B5014849).

\section{Availability of data and materials}

This study used National Sample Cohort data (Data No. NHIS-2016-2-103), provided by the National Health Insurance Service, South Korea.

\section{Authors' contributions}

JK Choi developed the analysis plan, interpreted analyses, and drafted the article. YT Kim supervised and approved article. HI Kweon revised the article. EC Park reviewed and approved the article. JH-Lee and SH Choi helped develop the analysis plan, interpreted analyses, drafted parts of the article, and approved it.

\section{Ethics approval and consent to participate}

All components and procedures of this study were approved by the Institutional Review Board (IRB) of the National Health Insurance Medical Center (NHIMC) (IRB File No.: NHIMC 2016-03-013). Our study utilized secondary data reported on the aggregate level, and each case in dataset was converted to prevent identification. So, it was not included informed consents of each patient.

Consent for publication

Not applicable.

Competing interests

The authors declare that they have no competing interests.

\section{Publisher's Note}

Springer Nature remains neutral with regard to jurisdictional claims in published maps and institutional affiliations.

\section{Author details}

'Department of Periodontology, Yonsei University College of Dentistry, Seoul, Korea. ${ }^{2}$ Department of Periodontology, National Health Insurance Service Ilsan Hospital, Goyang, Korea. ${ }^{3}$ Department of Preventive Medicine and Institute of Health Services Research, Yonsei University College of Medicine, Seoul, Korea. ${ }^{4}$ Institute of Health Services Research, Yonsei University College 
of Medicine, Seoul, Korea. ${ }^{5}$ Department of Periodontology, Yonsei University College of Dentistry, 50 Yonsei-ro, Seodaemun-gu, Seoul 03722, Korea. ${ }^{6}$ Department of Periodontology, Wonkwang University Daejeon Dental Hospital, Wonkwang University College of Dentistry, 77, Dunsan-ro, Seo-gu, Daejeon 35233, Korea.

Received: 26 October 2016 Accepted: 28 August 2017

Published online: 11 September 2017

\section{References}

1. Barrett-Connor E. The economic and human costs of osteoporotic fracture. Am J Med. 1995;98(2A):3S-8S.

2. Bonura F. Prevention, screening, and management of osteoporosis: an overview of the current strategies. Postgrad Med. 2009;121(4):5-17.

3. Nih Consensus Development Panel on Osteoporosis Prevention D, Therapy. Osteoporosis prevention, diagnosis, and therapy. JAMA. 2001;285(6):785-95.

4. Shin CS, Choi HJ, Kim MJ, Kim JT, Yu SH, Koo BK, et al. Prevalence and risk factors of osteoporosis in Korea: a community-based cohort study with lumbar spine and hip bone mineral density. Bone. 2010;47(2):378-87.

5. Brenneman SK, Barrett-Connor E, Sajjan S, Markson LE, Siris ES. Impact of recent fracture on health-related quality of life in postmenopausal women. J Bone Miner Res. 2006;21(6):809-16.

6. Lee JH, Oh JY, Youk TM, Jeong SN, Kim YT, Choi SH. Association between periodontal disease and non-communicable diseases: A 12-year longitudinal health-examinee cohort study in South Korea. Medicine (Baltimore). 2017; 96(26):e7398.

7. Loe H, Anerud A, Boysen H, Morrison E. Natural history of periodontal disease in man. Rapid, moderate and no loss of attachment in Sri Lankan laborers 14 to 46 years of age. J Clin Periodontol. 1986;13(5):431-45.

8. Soder $\mathrm{PO}$, Jin $\mathrm{L}$, Soder B, Wikner S. Periodontal status in an urban adult population in Sweden. Community Dent Oral Epidemiol. 1994;22(2):106-11.

9. Papapanou PN. Periodontal diseases: epidemiology. Ann Periodontol. 1996; 1(1):1-36.

10. Petersen PE, Bourgeois D, Ogawa H, Estupinan-Day S, Ndiaye C. The global burden of oral diseases and risks to oral health. Bull World Health Organ. 2005;83(9):661-9.

11. Kassebaum NJ, Bernabe E, Dahiya M, Bhandari B, Murray CJ, Marcenes W. Global burden of severe periodontitis in 1990-2010: a systematic review and meta-regression. J Dent Res. 2014;93(11):1045-53.

12. Lee JH, Lee JS, Park JY, Choi JK, Kim DW, Kim YT, et al. Association of Lifestyle-Related Comorbidities With Periodontitis: A Nationwide Cohort Study in Korea. Medicine (Baltimore). 2015;94(37):e1567.

13. Lee JH, Lee JS, Choi JK, Kweon HI, Kim YT, Choi SH. National dental policies and socio-demographic factors affecting changes in the incidence of periodontal treatments in Korean: A nationwide population-based retrospective cohort study from 2002-2013. BMC Oral Health. 2016;16(1):118.

14. Son MS, Seong SC. National Health Insurance Statistical Yearbook. Seoul: Health Insurance Review \& Assessment Service, National Health Insurance Service; 2015.

15. Caraballo PJ, Heit JA, Atkinson EJ, Silverstein MD, O'Fallon WM, Castro MR, et al. Long-term use of oral anticoagulants and the risk of fracture. Arch Intern Med. 1999;159(15):1750-6.

16. Lee RH, Lyles KW, Colon-Emeric C. A review of the effect of anticonvulsant medications on bone mineral density and fracture risk. Am J Geriatr Pharmacother. 2010;8(1):34-46.

17. Canalis E, Delany AM. Mechanisms of glucocorticoid action in bone. Ann N Y Acad Sci. 2002;966:73-81

18. Ebeling PR, Daly RM, Kerr DA, Kimlin MG. Building healthy bones throughout life: an evidence-informed strategy to prevent osteoporosis in Australia. Med J Aust. 2013;199(7 Suppl):S1.

19. Body JJ. How to manage postmenopausal osteoporosis? Acta Clin Belg. 2011;66(6):443-7.

20. Guiglia R, Di Fede O, Lo Russo L, Sprini D, Rini GB, Campisi G. Osteoporosis, jawbones and periodontal disease. Med Oral Patol Oral Cir Bucal. 2013;18(1):e93-9.

21. Luo K, Ma S, Guo J, Huang Y, Yan F, Xiao Y. Association between postmenopausal osteoporosis and experimental periodontitis. Biomed Res Int. 2014;2014:316134.

22. Lai H, Lo MT, Wang PE, Wang TT, Chen TH, Wu GH. A community-based epidemiological study of periodontal disease in Keelung, Taiwan: a model from Keelung community-based integrated screening programme (KCIS No. 18). J Clin Periodontol. 2007;34(10):851-9.
23. Khader Y, Khassawneh B, Obeidat B, Hammad M, El-Salem K, Bawadi H, et al, Periodontal status of patients with metabolic syndrome compared to those without metabolic syndrome. J Periodontol. 2008;79(11):2048-53.

24. Lee JH, Choi JK, Kim SH, Cho KH, Kim YT, Choi SH, et al. Association between periodontal flap surgery for periodontitis and vasculogenic erectile dysfunction in Koreans. J Periodontal Implant Sci. 2017:47(2):96-105.

25. Lin TH, Lung CC, Su HP, Huang JY, Ko PC, Jan SR, et al. Association between periodontal disease and osteoporosis by gender: a nationwide populationbased cohort study. Medicine (Baltimore). 2015;94(7):e553.

26. Charlson ME, Pompei $P$, Ales KL, Mackenzie CR. A new method of classifying prognostic comorbidity in longitudinal studies: development and validation. J Chronic Dis. 1987:40(5):373-83.

27. Sundararajan V, Henderson T, Perry C, Muggivan A, Quan H, Ghali WA. New ICD-10 version of the Charlson comorbidity index predicted in-hospital mortality. J Clin Epidemiol. 2004:57(12):1288-94.

28. Consultation WHOE. Appropriate body-mass index for Asian populations and its implications for policy and intervention strategies. Lancet. 2004; 363(9403):157-63.

29. Park SB, Kim J, Jeong JH, Lee JK, Chin DK, Chung CK, et al. Prevalence and Incidence of Osteoporosis and Osteoporotic Vertebral Fracture in Korea: Nationwide Epidemiological Study Focusing on Differences in Socioeconomic Status. Spine (Phila Pa 1976). 2016:41(4):328-36.

30. Choi YJ, Oh HJ, Kim DJ, Lee Y, Chung YS. The prevalence of osteoporosis in Korean adults aged 50 years or older and the higher diagnosis rates in women who were beneficiaries of a national screening program: the Korea National Health and Nutrition Examination Survey 2008-2009. J Bone Miner Res. 2012;27(9):1879-86.

31. Khosla S, Melton $\sqcup J$ 3rd, Riggs BL. Osteoporosis: gender differences and similarities. Lupus. 1999;8(5):393-6.

32. Harman SM, Tsitouras PD. Reproductive hormones in aging men. I. Measurement of sex steroids, basal luteinizing hormone, and Leydig cell response to human chorionic gonadotropin. J Clin Endocrinol Metab. 1980; 51(1):35-40.

33. Riggs BL, Wahner HW, Dunn WL, Mazess RB, Offord KP, Melton $L$ 3rd. Differential changes in bone mineral density of the appendicular and axial skeleton with aging: relationship to spinal osteoporosis. J Clin Invest. 1981; 67(2):328-35.

34. Jones G, Nguyen T, Sambrook P, Kelly PJ, Eisman JA. Progressive loss of bone in the femoral neck in elderly people: longitudinal findings from the Dubbo osteoporosis epidemiology study. BMJ. 1994;309(6956):691-5.

35. Felson DT, Zhang Y, Hannan MT, Anderson JJ. Effects of weight and body mass index on bone mineral density in men and women: the Framingham study. J Bone Miner Res. 1993;8(5):567-73.

36. Fitzpatrick SK, Casemyr NE, Zurakowski D, Day CS, Rozental TD. The effect of osteoporosis on outcomes of operatively treated distal radius fractures. J Hand Surg Am. 2012;37(10):2027-34.

37. Hofbauer LC, Brueck CC, Singh SK, Dobnig H. Osteoporosis in patients with diabetes mellitus. J Bone Miner Res. 2007:22(9):1317-28.

38. Martinez-Maestre MA, Gonzalez-Cejudo C, Machuca G, Torrejon R, CasteloBranco C. Periodontitis and osteoporosis: a systematic review. Climacteric 2010;13(6):523-9.

39. Bertolaccini L, Terzi A, Rizzardi G, Gorla A, Viti A, Palmisano S, et al. Risk is not our business: safety of thoracic surgery in patients using antiplatelet therapy. Interact Cardiovasc Thorac Surg. 2012;14(2):162-6.

40. Scheiber MD, Liu JH, Subbiah MT, Rebar RW, Setchell KD. Dietary inclusion of whole soy foods results in significagent reductions in clinical risk factors for osteoporosis and cardiovascular disease in normal postmenopausal women. Menopause. 2001;8(5):384-92.

41. Hwang DK, Choi HJ. The relationship between low bone mass and metabolic syndrome in Korean women. Osteoporos Int. 2010;21(3):425-31. 